\title{
Implementasi Client-Server \\ Pada Sistem Informasi Pengolahan Nilai Siswa Menggunakan Object-Oriented Programming
}

\author{
Ullya Mega Wahyuni ${ }^{1 *}$, Fitrilina ${ }^{2}$ \\ ${ }^{1}$ Jurusan Sistem Informasi FTI Universitas Andalas \\ ${ }^{2}$ Prodi Teknik Elektro Fakultas Teknik Universitas Bengkulu \\ E-mail : ullyamegawahyuni@it.unand.ac.id
}

\begin{abstract}
The use of information technology in educational institutions be necessary for work to be efficient and flexible. The process of reporting student data and assessment results at SMA Negeri 1 Dharmasraya is still manual using paper (paper-based), and there is no specific storage for the database. To make reports on student learning outcomes and share resources easier then an information system was built on a client-server network using object-oriented programming with a centralized database so that the stored data can be organized. The build systems using the System Development Life Cycle waterfall model, which starts from the analysis, design, coding, testing, and maintenance. The results of this study are the establishment of a multiuser system that implements the use of client-server computer networks to process student grades.

Key Words: Client-Server, Information Systems, OOP
\end{abstract}

\section{ABSTRAK}

Pemanfaatan teknologi informasi di lembaga pendidikan sangat diperlukan agar pekerjaan menjadi lebih efisien dan fleksibel. Proses pelaporan data kesiswaan dan hasil penilaian pada sekolah SMA Negeri 1 Dharmasraya masih dilakukan secara manual menggunakan kertas (paper-based) dan belum ada storage khusus untuk database. Untuk memudahkan dalam pengolahan nilai siswa dan sharing resource, maka dibangun sebuah sistem informasi berbasis client-server dengan menggunakan object-oriented programming dengan database terpusat sehingga data yang tersimpan bisa terorganisir. Sistem yang dibangun menggukan model waterfall System Development Life Cycle yang dimulai dari analisa, desain, pengkodean, pengujian, dan maintenance. Hasil dari penelitian ini adalah terbentuknya sistem multiuser yang menerapkan pemakaian jaringan komputer client-server untuk pengolahan nilai siswa.

Kata kunci: Client-Server, Sistem Informasi, OOP

\section{Pendahuluan}

Pesatnya kemajuan teknologi di Indonesia yang semakin canggih dapat mempengaruhi segala aspek kehidupan manusia. Baik para ahli, anak muda, orang tua dan orang awam pun menggunakan teknologi dalam berbagai kegiatan. Hal ini membuat teknologi informasi di era revolusi industri 4.0 menjadi kebutuhan dasar setiap orang dan sangat berperan penting terutama di bidang pendidikan. Penggunaan teknologi informasi dalam pengolahan data nilai siswa di SMAN 1 Sungai Rumbai memberikan kemudahan dalam manajemen data, menghemat biaya dan waktu, serta dengan sistem yang terintegrasi dapat meningkatkan kecepatan dalam merespon sesuatu.

Proses penyimpanan informasi terkait kegiatan pengolahan nilai hasil belajar siswa di SMAN 1 Sungai Rumbai masih belum terkomputerisasi dengan baik. Dalam pengolahan data siswa masih ada sebagian guru melakukan secara manual menggunakan kertas (paper based) dan sebagiannya lagi menggunakan laptop masing-masing. Penyimpanan data siswa saat ini masih belum menggunakan storage khusus seperti database. Sehingga ketika data lama dibutuhkan, maka timbul permasalahan seperti terjadinya keterlambatan dalam penyerahan laporan hasil belajar siswa kepada pimpinan. Selain itu pencarian data juga memakan waktu lama atau tidak ditemukannya data yang diminta. Hal demikian dinilai tidak efisien dan kurang efektif lagi.

Penerapan sistem informasi pengolahan nilai siswa dengan database terpusat memberikan kemudahan bagi user dalam pengolahan data. Adanya fungsi multiuser pada sistem ini memberikan hak akses bagi para siswa 


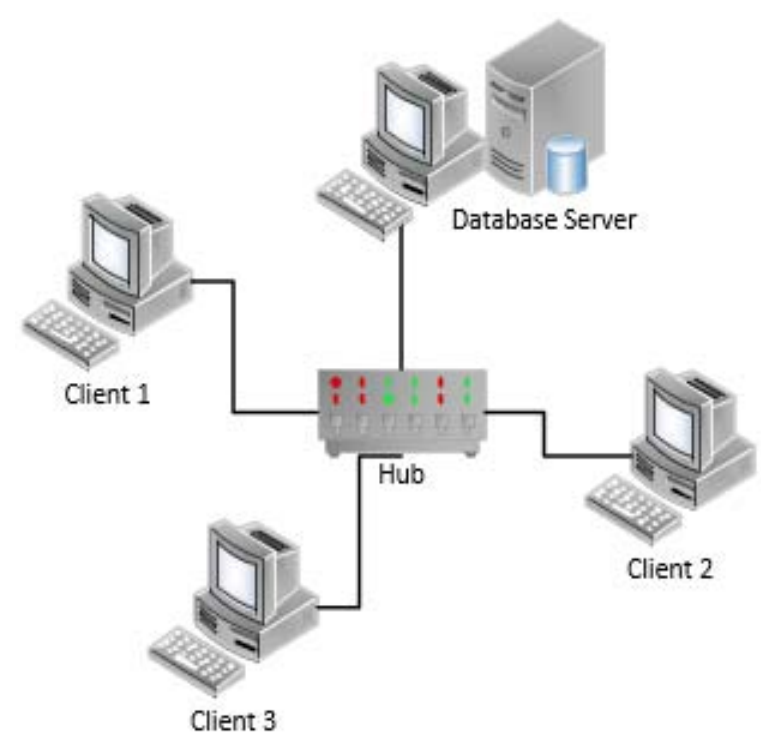

Gambar 1. Arsitektur Client Server

untuk bisa melihat progres hasil belajar selama masa study yang nantinya diharapkan menjadi motivasi untuk terus giat belajar.

Dengan menerapkan pemakaian jaringan komputer berbasis client-server untuk pengolahan data yang dibangun dengan menggunakan object-oriented programming diharapkan dapat memberikan kemudahan dalam sharing resource. Implementasi networking berbasis client server menjadikan sistem saling terhubung satu sama lain dengan menggunakan jalur transmisi membentuk satu sistem [1]. Pada sistem operasi windows, terdapat Command Prompt sebagai fitur untuk mengirim pesan ke komputer lain yang dinamakan Net Send. Net Send merupakan service yang dimiliki windows untuk mengirim pesan ke komputer tujuan [2]. Penggunaan Net Send harus melewati beberapa tahapan agar pesan yang dikirim bisa sampai ke tujuan. Oleh karena itu, agar memudahkan para guru dalam bertukar informasi penggunaan Net Send dapat digantikan dengan socket programming yang ada pada Java dengan konsep client-server.

\section{TINJAUAN PUSTAKA}

\section{A. Arsitektur Client-Server}

Arsitektur client-server merupakan jaringan komputer yang membedakan fungsi komputer menjadi komputer client dan komputer server [3]. Pada aplikasi yang menggunaan arsitektur client-server, aplikasi dapat beroperasi secara mandiri walaupun berada ditempat yang berbeda. Cara kerja aplikasi client server yaitu

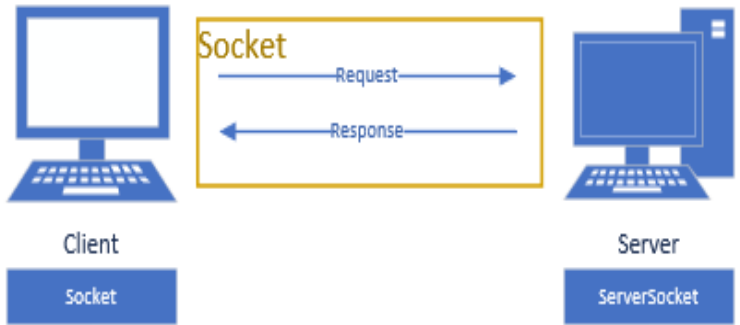

Gambar 2. Ilustrasi socket pada Client Server

database server akan menerima request berupa perintah-perintah dari komputer client kemudian database server akan mengirimkan jawabannya ke komputer client. Komputer pertama sebagai server (back end) berupa Data Base Management System (DBMS). Komputer kedua dan seterusnya disebut client (front end). Aplikasi yang dibangun ditulis dengan menggunakan konsep object-oriented programming.

\section{B. Object-Oriented Programming (OOP)}

Object-Oriented Programming merupakan metode pemograman yang berorientasi kepada objek [4]. Dalam OOP, programmer yang sama atau berbeda dapat mengembangan sistem yang ada dimana class dan obyek dapat digunakan berulang-ulang atau menambahkan obyek baru pada sistem yang ada. Jika terjadi permasalahan, sistem lebih mudah diatasi. Untuk pengembangan sistem yang kompleks, bahasa pemograman yang mendukung Object Oriented Programming sangat efektif digunakan [5].

\section{Socket Programming}

Socket adalah sebuah terminal penghubung antara client dan server untuk melakukan komunikasi. Pengembangan sebuah software berbasis client-server dapat menggunakan socket programming untuk melakukan komunikasi dua arah[6]. Komunikasi dengan socket konsepnya hampir sama seperti operasi I/O. Jadi aplikasi dapat membaca atau menulis terhadap socket tersebut sama mudahnya seperti ketika aplikasi menulis sesuatu dari atau ke dalam file. Socket juga bisa diibaratkan sebagai kunci yang memberikan akses menuju port yang tepat. Pada java, untuk file sharing pada sebuah jaringan dengan menggunakan Java Socket Programming dapat dilakukan secara sederhana dengan memanfaatkan paket java.net dan Socket Class yang sudah tersedia. Protokol yang digunakan pada komunikasi socket pada sistem yang dibangun adalah TCP (Transmission Control Protocol). 


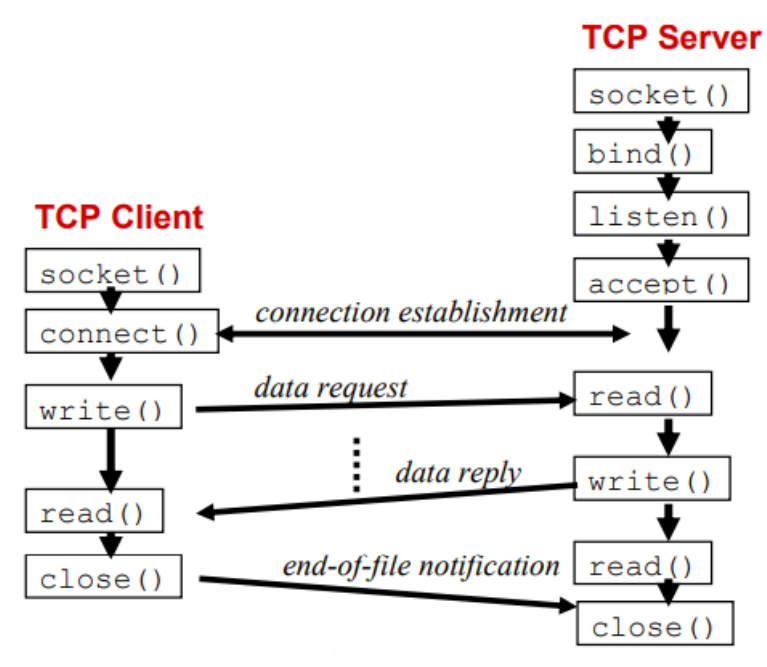

Sumber: www.javaworld.com

Gambar 3. Interaksi TCP Client-Server

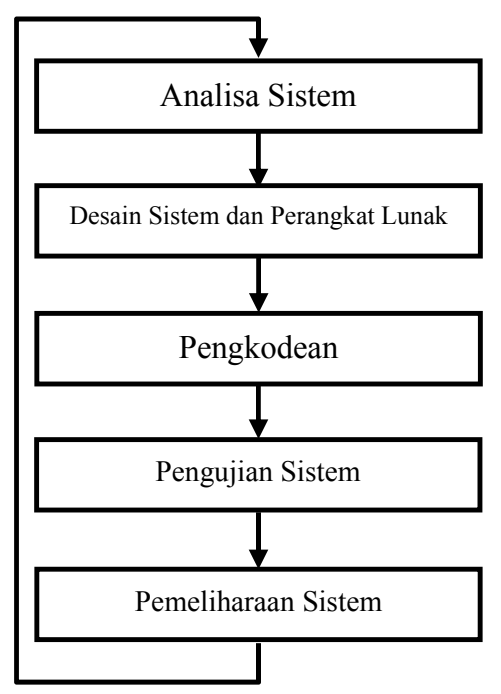

Gambar 4. Kerangka Kerja Penelitian

\section{METODE RISET}

Metode penelitian yang digunakan berdasarkan rekayasa perangkat lunak (Software Engineering) adalah mengunakan model waterfall SDLC (System Development Life Cycle). Pada SDLC sistem dikerjakan secara berurutan dimulai dari menganalisa sistem, mendesain sistem, melakukan pengkodean, pengujian, dan pemeliharaan [7].

\section{Analisa Sistem}

Pada tahapan ini, langkah awal yang dilakukan adalah menganalisa permasalahan yang telah didefinisikan secara rinci. Untuk kebutuhan sistem baik berupa software maupun hardware juga dianalisa pada tahapan

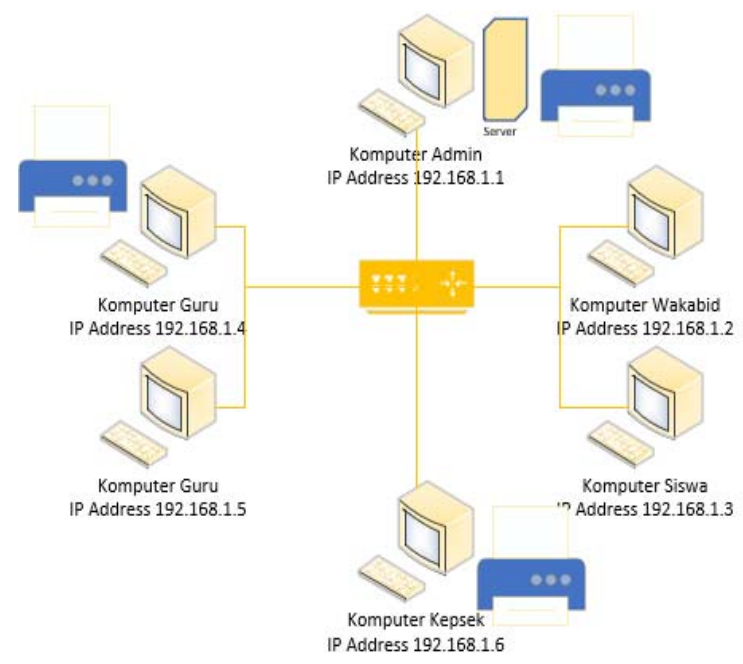

Gambar 5. Konfigurasi Jaringan SMAN 1 Sei.Rumbai

ini. Fase ini sangat penting karena akan menentukan hasil desain dari sebuah sistem yang akan dibangun. Sistem yang dibangun adalah sistem informasi pengolahan nilai berbasis client-server dengan menggunakan bahasa pemograman Java.

2. Desain Sistem

Desain sistem bertujuan untuk memberikan gambaran umum tentang desain perangkat lunak yang akan dibangun. Hasil dari analisa dibuatkan rancangan interfacenya dan struktur program yang akan dibangun. Pemodelan desain program berorientasi objek (OOP) menggunakan metodologi Unified Modeling Language (UML), diagram yang akan digunakan diantaranya; Use Case Diagram, Activitiy Diagram dan Class Diagram.

\section{Pengkodean}

Pada tahapan ini, desain sistem yang sudah terbentuk di aplikasikan ke dalam bahasa pemrograman yang digunakan dalam bentuk source code/syntax. Pembangunan sistem ini menggunakan bahasa pemrograman Java yang mendukung konsep OOP dengan database terpusat. Karena sistem informasi yang dibangun berbasis client-server, maka digunakan socket programming untuk membuat menu chat dan transfer file. Implementasi networkingnya, saat pengkodean menggunakan class Socket dan ServerSocket yang sudah ada di Java.

\section{Pengujian}

Untuk memastikan apakah output yang dihasilkan sesuai berdasarkan input dari user maka dilakukan pengujian pada logika internal dan sistem secara keseluruhan dengan menggunakan metode blackbox testing.

\section{Maintenance}

Program yang dibangun akan mengalami penyesuaian atau perubahan seiring penggunaan aplikasi. 


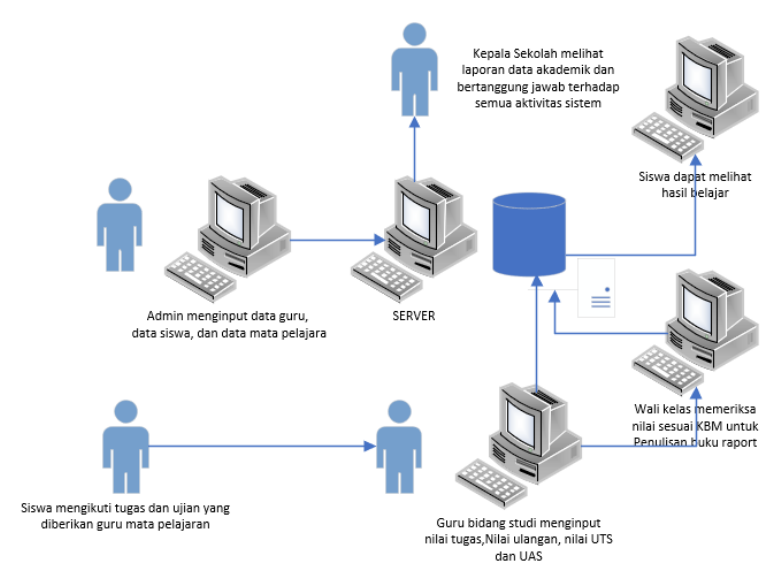

Gambar 6. Analisa Proses Bisnis Sistem yang diusulkan

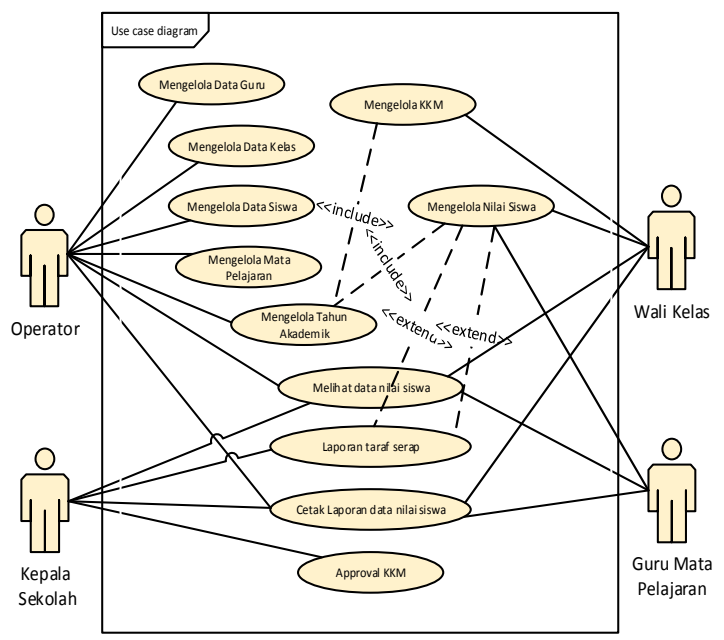

Gambar 3. Use Case Diagram

\section{HASIL DAN PEMBAHASAN}

\section{A. Desain Sistem}

Cara kerja dari sistem informasi pengolahan nilai siswa berbasis client-server yang diusulkan dapat dilihat pada gambar 5 .

Bentuk jaringan yang dipakai pada sistem ini adalah jaringan Local Area Network (LAN) dengan menggunakan topologi star. Untuk implementasi networkingnya, pada java sudah terdapat package khusus yang dapat digunakan dalam pembuatan aplikasi yang memanfaatkan jaringan yaitu java.net. Packet java.net menyediakan banyak class yang dapat digunakan untuk membuat aplikasi jaringan pada Java. Pemilihan dan penggunaanya bisa disesuaikan dengan kebutuhan user.

Pada sistem yang dibangun menggunakan dua class yang terdapat pada Packet java.net yaitu Socket dan ServerSocket. ServerSocket digunakan pada server untuk listen koneksi, sedangkan pada client digunakan

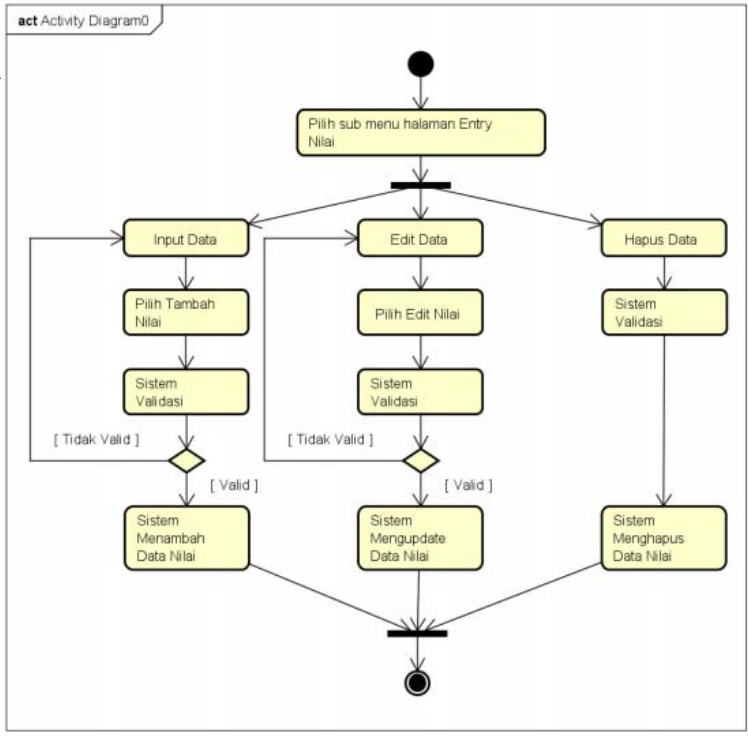

Gambar 4. Activity Diagram

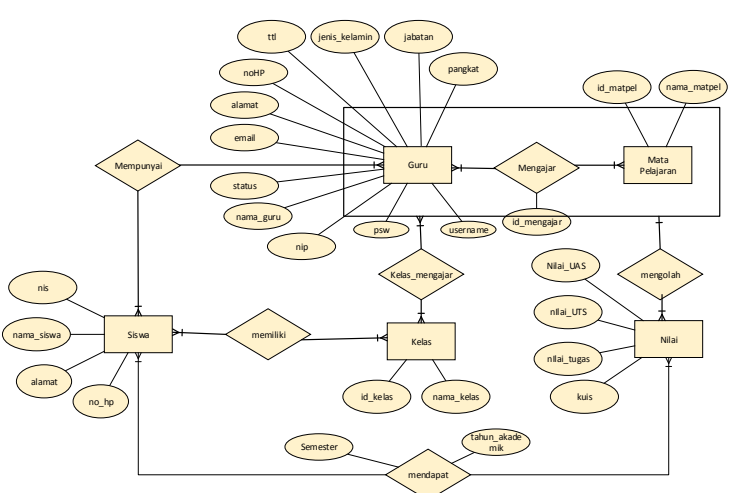

Gambar 5. Entity Relationship Diagram

Untuk memodelkan perilaku Use Cases dan objects di dalam sistem maka digunakan Activity Diagram. Salah satu alur kerja urutan aktivitas aktor untuk entry nilai pada sistem yang dirancang dapat dilihat seperti gambar 4

Gambaran perancangan basis data yang akan dibangun menggunakan model Entity Relationship Diagram (ERD) yang dapat dilihat pada gambar 5 .

\section{B. Implementasi}

Untuk mensetting client-server pada sistem informasi yang dibangun, yang perlu diperhatikan adalah setting database MySql Server. Saat melakukan coding, agar sistem bersifat client server maka host-nya di ubah dengan IP komputer server $\&$ nama database disesuaikan dengan nama database dari project yang sedang dibangun.

Untuk menjalankan fungsi chat room, maka digunakan class socket dan SocketServer yang sudah disediakan di package java.net. Sistem kerja dari chat 


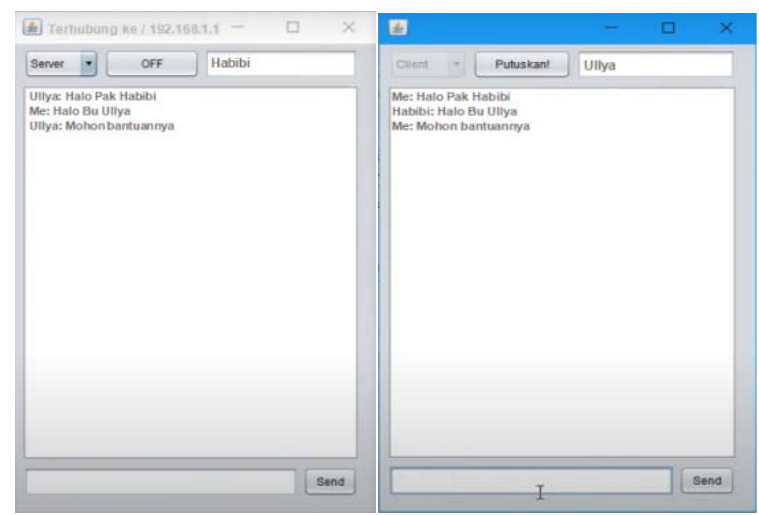

Gambar 6. Tampilan Interface Chat Room

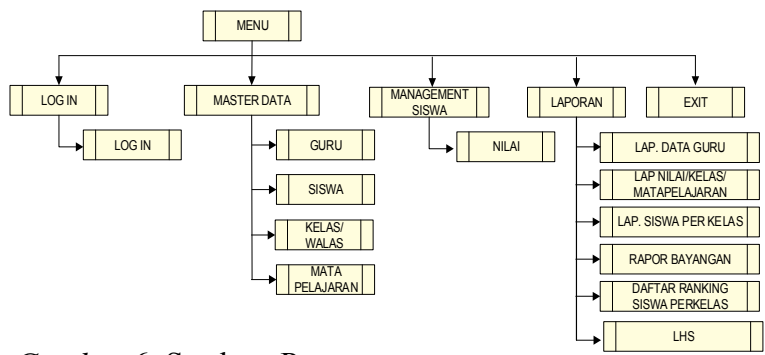

Gambar 6. Struktur Program

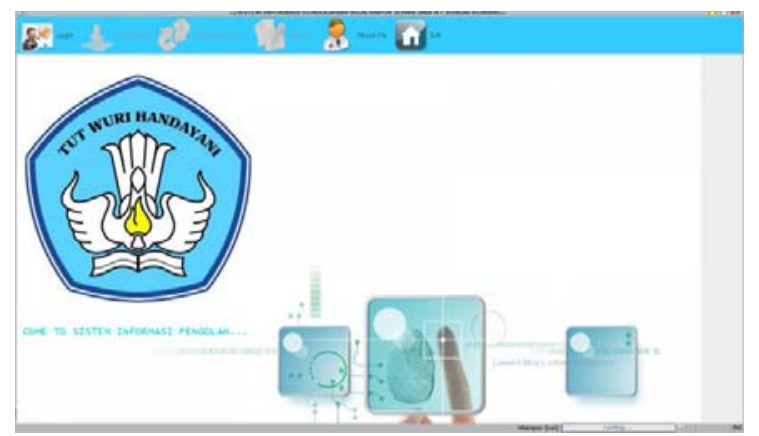

Gambar 6. Tampilan Menu Utama

room ini sama seperti grup chat di sosial media. Jika seseorang pengguna mengirim pesan, maka setiap pengguna lain pada grup tersebut mampu melihatnya.

Pada awal program Client dibuka, maka pengguna akan langsung diminta untuk memasukkan IP Address dari server. Sehingga, program Server sudah harus berjalan pada komputer yang berfungsi sebagai server sebelum program Client dapat berjalan. Jika program Client dimulai sebelum program Server maka akan terjadi error.

Pada gambar 6 menampilkan struktur program dari sistem yang dibangun sehingga terlihat hirarki atau tingkatan dari program yang akan dirancang.

Setiap jenis pengguna memiliki halaman yang berbeda karena mempunyai hak akses yang berbeda. Contohnya pada halaman operator, semua menu yang ada di sistem akan terlihat. Sedangkan akun guru hanya akan tampil menu yang diijinkan saja (enable menu).

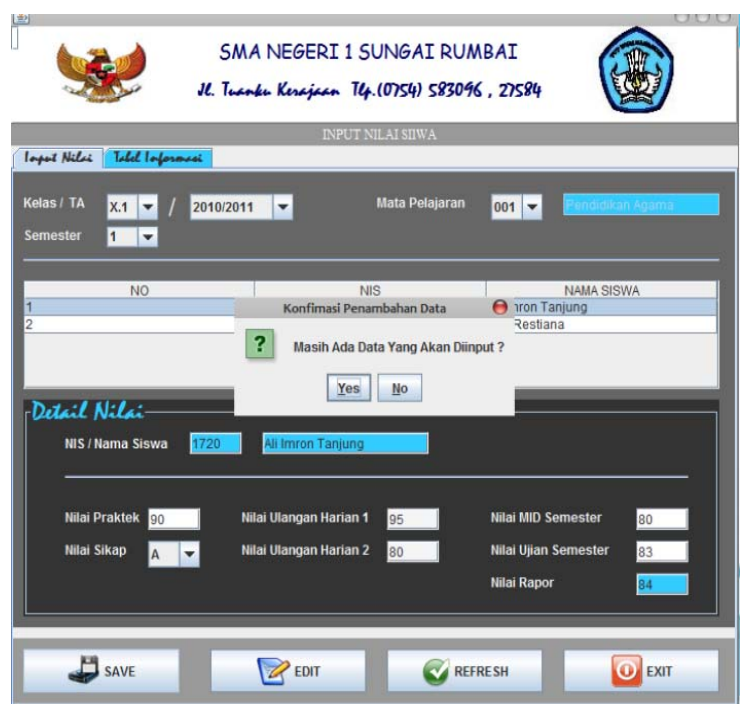

Gambar 7. Form Entry Nilai

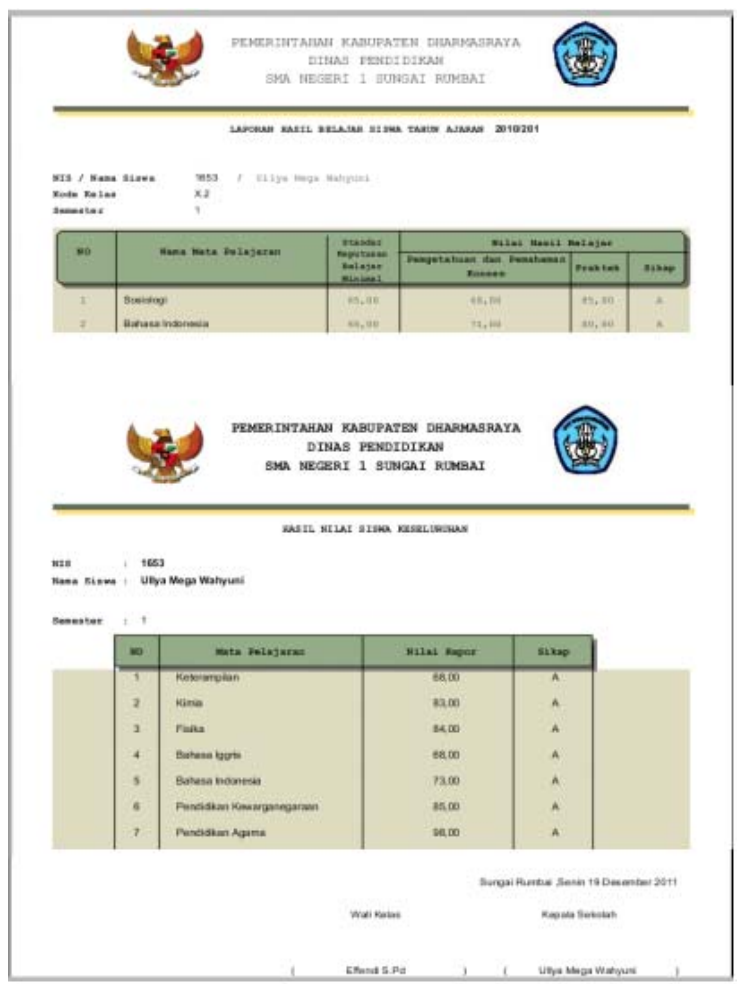

Gambar 8. Laporan Hasil Belajar Siswa

Pada gambar 7 terlihat form input nilai siswa, form ini berfungsi menginput nilai siswa yang langsung terekam kedalam database. Form ini memiliki tombol Save untuk menyimpan, tombol Edit untuk mengupdate data, tombol Refresh untuk mengosongkan form jika dilakukan pengisian data selanjutnya, serta tombol Exit untuk kembali kemenu utama.

Salah satu bentu laporan hasil belajar siswa, dapat terlihat pada gambar 8 . 
TABEL 1

Pengujian Blackbox Testing

\begin{tabular}{|c|c|c|c|}
\hline No & Fungsi & Butir Uji & Hasil Uji \\
\hline 1 & $\begin{array}{l}\text { Input, edit, } \\
\text { hapus, } \\
\text { update data }\end{array}$ & $\begin{array}{l}\text { Isi form dengan data } \\
\text { baru. Hasilnya akan } \\
\text { tersimpan jika } \\
\text { menggunakan tombol } \\
\text { save, tombol Edit } \\
\text { untuk mengupdate } \\
\text { data, tombol Refresh } \\
\text { untuk mengosongkan } \\
\text { form jika dilakukan } \\
\text { pengisian } \\
\text { selanjutnya }\end{array}$ & Berhasil \\
\hline 2 & $\begin{array}{l}\text { Menu Input } \\
\text { Nilai }\end{array}$ & $\begin{array}{l}\text { Login dengan akun } \\
\text { yang berbeda apakah } \\
\text { menu input nilai siswa } \\
\text { bisa diakses atau tidak } \\
\text { karena menu input } \\
\text { nilai sifat aksesnya } \\
\text { terbatas sehingga } \\
\text { membutuhkan } \\
\text { username dan } \\
\text { password khusus } \\
\text { untuk bisa masuk di } \\
\text { menu ini. }\end{array}$ & Berhasil \\
\hline 3 & $\begin{array}{l}\text { Menu lihat } \\
\text { nilai siswa }\end{array}$ & $\begin{array}{l}\text { Menampilkan daftar } \\
\text { nilai akhir siswa yang } \\
\text { bisa diakses oleh } \\
\text { semua user client. }\end{array}$ & Berhasil \\
\hline 4 & $\begin{array}{l}\text { Cetak } \\
\text { laporan }\end{array}$ & $\begin{array}{l}\text { Pada menu laporan, } \\
\text { data yang diinginkan } \\
\text { siap untuk dicetak baik } \\
\text { dalam bentuk paper } \\
\text { atau pdf. }\end{array}$ & Berhasil \\
\hline 5 & Login & $\begin{array}{l}\text { Setiap jenis pengguna } \\
\text { memiliki halaman } \\
\text { utama yang berbeda } \\
\text { karena mempunyai hak } \\
\text { akses yang berbeda. } \\
\text { Menu yang tampil } \\
\text { hanya menu yang } \\
\text { diijinkan saja (enable } \\
\text { menu). }\end{array}$ & Berhasil \\
\hline 6 & $\begin{array}{l}\text { sharing } \\
\text { resource }\end{array}$ & $\begin{array}{l}\text { Melakukan pencarian } \\
\text { data dengan } \\
\text { menggunakan } \\
\text { komputer di area yang } \\
\text { berbeda. }\end{array}$ & Berhasil \\
\hline 7 & Chat Room & $\begin{array}{l}\text { Pengguna bisa saling } \\
\text { chatting dalam grup } \\
\text { chat }\end{array}$ & Berhasil \\
\hline
\end{tabular}

\section{Pengujian}

Pengujian dengan menggunakan blackbox testing bertujuan untuk memastikan apakah keluaran sistem sudah sesuai inputan dari user. Pengujian blackbox testing dilakukan pada logika internal dan sistem secara keseluruhan.

\section{PENUTUP}

\section{A. Kesimpulan}

Berdasarkan perancangan, implementasi dan hasil pengujian yang telah dilakukan, maka dapat diambil kesimpulan bahwa Implementasai jaringan komputer berbasis Client server sangat cocok diterapkan di SMAN Dharmasraya karena dapat mempermudah dan mempercepat sharing resource antar pengguna. Aplikasi ini dapat memfasilitasi guru dalam proses pengolahan nilai siswa dengan menggunakan menu Nilai Siswa yang dilengkapi dengan fitur "Input Nilai" sehingga seluruh nilai siswa di SMAN 1 Dharmasraya dapat terintegrasi. Hal ini dapat mengurangi resiko hilang atau rusaknya data nilai siswa karena sudah memiliki storage khusus untuk penyimpanan data berupa databese terpusat.

\section{B. Saran}

Untuk penelitian selanjutnya diharapkan sistem informasi ini dapat dikembangan lebih kompleks berbasis web atau server dan berjalan dalam jaringan internet. Selain itu keamanan data juga perlu diperhatikan karena keluar masuknya data meyebabkan port terbuka. Pengiriman data yang bersifat sensitif atau rahasia menjadi pertimbangan dalam keamanan datanya karena sistem yang berjalan masih belum disertakan fungsi enkripsi.

\section{REFERENSI}

[1] N. Anwar and I. Riadi, "Analisis Arsitektur Client Server Menggunakan Database Terpusat (Studi Kasus pada SMP Muhammadiyah Purwodadi Purworejo)," Sarj. Tek. Inform., vol. 1, no. 2, pp. 647-659, 2013, doi: 10.12928/jstie.v1i2.2589.

[2] B. K. Simpony, "Pemanfaatan Windows Socket Control Untuk Aplikasi Intranet Messenger," IJCIT (Indonesian J. Comput. Inf. Technol., vol. 2, no. 1, pp. 61-67, 2017.

[3] D. Sukrianto, "Summary for Policymakers," in Climate Change 2013 - The Physical Science Basis, vol. 53, no. 9, Intergovernmental Panel on Climate Change, Ed. Cambridge: Cambridge University Press, 2019, pp. 1-30.

[4] U. Mega Wahyuni, "Penerapan Sistem Pakar Dalam Pengembangan Budidaya Padi Teknologi Salibu Dengan Metode Forward Chaining," Maj. 
Ilm., vol. 25, no. 1, pp. 88-98, 2018.

[5] N. A. Ilham and Naziro, "Implementasi Konsep Pemrograman Berorientasi Objek Pada Aplikasi Sistem Parkir Menggunakan Bahasa Pemrograman Java," J. Edukasi Elektro, vol. 3, no. 2, pp. 63-69, 2020, doi: $10.21831 /$ jee.v3i2.28293.

[6] B. K. Simpony, "Remote Registry Editor," J. Inform., vol. 2, no. 1, 2016, doi: 10.31311/ji.v2i1.56.

[7] Y. Firmansyah and U. Udi, "Penerapan Metode SDLC Waterfall Dalam Pembuatan Sistem Informasi Akademik Berbasis Web Studi Kasus Pondok Pesantren Al-Habib Sholeh Kabupaten Kubu Raya, Kalimantan Barat," J. Teknol. dan Manaj. Inform., vol. 4, no. 1, Nov. 2017, doi: 10.26905/jtmi.v4i1.1605. 